\title{
The fleA GeNUS SIGMACTENUS (SIPHONAPTERA: LEPTOPSYLLIDAE): THREE NEW TAXA FROM SULAWESI, UPDATED IDENTIFICATION KEY, AND DISTRIBUTION MAP FOR ALL KNOWN SPECIES AND SUBSPECIES
}

\author{
DURDEN L.A.* \& BEAUCOURNU J.-C.**
}

\section{Summary :}

One new species and two new subspecies of fleas are described. These are S. sulawesiensis n. sp. from North and Central Sulawesi, S. alticola pilosus n. ssp. from Central Sulawesi, and S. alticola crassinavis $n$. ssp. from North Sulawesi. All three of these new taxa are ectoparasites of native, endemic murine rodents. Two of the new taxa, S. sulawesiensis and S. alticola crassinavis, coexist on the same mountain, Gunung Moajat, in North Sulawesi. The related S. alticola alticola, which becomes the nominate subspecies, parasitises the murine rodent Maxomys alticola in northern Borneo (Sabah) and it is hypothesized that Sigmactenus first colonized Sulawesi as an ectoparasite of ancestral Maxomys, or perhaps Rattus, as these murines dispersed from southeast Asia to Sulawesi; 15 endemic murine rodent species belonging to these two genera are known to currently inhabit Sulawesi. An identification key and distribution map are included for all known species and subspecies of Sigmactenus. In addition to the three new taxa and S. a. alticola, these include:

S. celebensis from South Sulawesi, S. timorensis from Timor,

S. toxopeusi from New Guinea, and S. werneri from the

Philippines (Mindanao and Negros).

KEY WORDS : Sigmactenus, new species, new subspecies, Sulawesi, Indonesia, identification key, geographical distribution.

\section{INTRODUCTION}

$\mathrm{M}$ embers of the leptopsyllid flea genus Sigmactenus Traub, 1950 are distributed on various islands in the Indo-Australian region where they mainly parasitise endemic murine rodents (Durden \& Beaucournu, 2000). The five currently recognised species and their geographical distributions are as follows: S. alticola Traub, 1954 from northern

\footnotetext{
* Institute of Arthropodology \& Parasitology, Georgia Southern University, P.O. Box 8056, Statesboro, Georgia 30460, USA. (Tel.: 912-681-0553 - Fax: 912-681-0559 - e-mail: ldurden@gsvms2.cc.gasou.edu).

** Laboratoire de Parasitologie et Zoologie appliquée, Faculté de Médecine, Université de Rennes, 2, avenue du Prof. Léon Bernard, 35043 Rennes Cedex, France (Tél. : 0299336832 - Fax: 0299336941 e-mail: jbeaucou@univ-rennes1.fr).

Correspondence: Lance Durden.
}

Résumé : LE GENRE SIGMACTENUS (SIPHONAPTERA: LEPTOPSYLLIDAE) TROIS NOUVEAUX TAXA DU SULAWESI, CLÉ D'IDENTIFICATION, ET CARTE DE DISTRIBUTION POUR TOUTES LES ESPĖCES ET SOUS-ESPĖCES CONNUES

Une espèce et deux sous-espèces nouvelles de puces sont décrites: S. sulawesiensis n. sp. du nord et du centre de l'île, S. alticola pilosus $n$. ssp. du centre et $\mathrm{S}$. alticola crassinavis $n$ ssp. du nord. Ces trois nouveaux taxa sont ectoparasites de rongeurs autochtones et endémiques. Deux d'entre eux, S. sulawesiensis et $\mathrm{S}$. a. crassinavis, sont sympatriques dans le même massif montagneux, Gunung Moajat, du nord de l'île. S. a. alticola, qui devient la forme nominative des deux sous- espèces, parasite le rongeur muriné Maxomys alticola dans le nord de Bornéo (Sabah) et nous émettons l'hypothèse que Sigmactenus colonisa primitivement le Sulawesi en tant qu'ectoparasite d'un ancestral Maxomys, ou peut-être Rattus, puisque ces murinés envahirent cette ile à partir de l'Asie du sud-est : 15 espèces endemiques de rongeurs murinés, appartenant à ces deux genres, sont actuellement connues du Sulawesi. Une clé d'identification et une carte de distribution sont données pour toutes les puces, espèces ou sous-espèces connues dans ce genre. En dehors des taxa décrits ici sont inclus: S. celebensis du Sulawesi méridional, S. timorensis de Timor, S. toxopeusi de Nouvelle-Guinée et S. werneri des Philippines (Mindanao et Negros).

MOTS CLÉS : Sigmactenus, espèce nouvelle, sous-espèces nouvelles, Sulawesi, Indonésie, clé d'identification, répartition géographique.

Borneo (Sabah), S. celebensis Lewis \& Jones, 1985 from South Sulawesi (Sulawesi Selatan), Indonesia, S. timorensis Durden \& Beaucournu, 2000 from Timor, Indonesia, S. toxopeusi Smit, 1953 (synonym: S. cavifrons Smit, 1975) from New Guinea, and S. werneri Traub, 1950 from the Philippines (Mindanao and Negros Islands). After examining a large series of Sigmactenus specimens from North and Central Sulawesi (Sulawesi Utara and Sulawesi Tengah), we have identified one new species and two new subspecies of fleas belonging to this genus. These three new taxa are described in this paper. Because we describe two of the new taxa as subspecies of $S$. alticola, the nominate subspecies of this taxon from Borneo now becomes $S$. alticola alticola Traub, 1954. In addition to describing the three new taxa, we also comment briefly on the likely mode of dispersal of Sigmactenus to Sulawesi and provide a distribution map for all currently recognised species in this genus. 
SIGMACTENUS SULAWESIENSIS N. SP.

\section{MATERIAL EXAMINED}

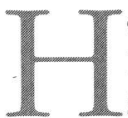
olotype male, on Bunomys fratrorum (Thomas, 1896) (prep. B98903), Indonesia, North (N.) Sulawesi, Gunung Moajat ( $\left.0^{\circ} 45^{\prime} \mathrm{N}, 124^{\circ} 25^{\prime} \mathrm{E}\right)$, 1,780 m, Aug. 1985, C.H.S. Watts (CHSW). Allotype female on Paruromys dominator (Thomas, 1921) (prep. LAD84), same locality, 1,650 m, Mar. 1985, L.A. Durden (LAD).

\section{Paratypes}

- On B. fratrorum: $1 \mathrm{~m}, 1 \mathrm{f}, \mathrm{N}$. Sulawesi, Gunung Moajat, 1,780 m, Aug. 1985, CHSW.

- On Bunomys penitus (Miller \& Hollister, 1921): $1 \mathrm{f}$, Central (C.) Sulawesi, Gunung Nokilalaki, 2,103 m, 28 Mar. 1975, G.G. Musser (GGM).

- On Eropeplus canus Miller \& Hollister, 1921: $1 \mathrm{f}, \mathrm{C}$. Sulawesi, Gunung Nokilalaki, 2,195 m, 23 Dec. 1975, GGM.

- On Maxomys musschenbroekii (Jentink, 1878): $1 \mathrm{~m}$, N. Sulawesi, Gunung Moajat, 1,780 m, 30 Jul. 1985, CHSW.

- On P. dominator. 3 m, 3 f, N. Sulawesi, Gunung Moajat, 1,780 m, Mar. 1985 (LAD) and Aug. 1985 (CHSW). C. Sulawesi: 1 m, 1 f, Gunung Kanino (1²1 ' S, $120^{\circ} 08^{\prime}$ E), 1,463 m \& 1,494 m, 25 Jan. 1975, GGM; $1 \mathrm{~m}$, Gunung Nokilalaki (10 $\left.16^{\prime} \mathrm{S}, 120^{\circ} 10^{\prime} \mathrm{E}\right), 2,073 \mathrm{~m}$, 7 Mar. 1975, GGM.

- On Prosciurillus leucomus (Forsten, 1839): 2 f, C. Sulawesi, Lake Lindu, Tomado (1 $\left.{ }^{\circ} 19^{\prime} \mathrm{S}, 120^{\circ} 03^{\circ} \mathrm{E}\right), 1,000 \mathrm{~m}$, 15 Aug. 1973, GGM.

Hosts and distribution

All six of the host species recorded for S. sulawesiensis are rodents that are endemic to Sulawesi. Further, four of the five host genera are endemic to Sulawesi; the exception, Maxomys, is also represented on mainland Southeast Asia, the Greater Sunda islands, and Palawan (Musser et al., 1979). Five of the six host species are murine rodents (Muridae: Murinae), whereas one (P. leucomus) is a pygmy tree squirrel (Rodentia: Sciuridae) (Musser, 1987). This new species is known from one locality in N. Sulawesi and three localities in C. Sulawesi at elevations ranging from $1,000 \mathrm{~m}$ to $2,195 \mathrm{~m}$.

\section{Etymology}

This species is named for the island it inhabits, i.e., Sulawesi, Indonesia.

Deposition of types

Holotype and allotype deposited in the U.S. National Musem of Natural History (Smithsonian Institution), Washington DC. Paratypes deposited in the American
Museum of Natural History, New York, the Museum National d'Histoire Naturelle, Paris, the Natural History Museum, London, the Museum Zoologicum Bogoriense, Indonesia, and in the collections of the authors.

\section{DESCRIPTION}

This species is unique in the genus Sigmactenus because it possesses only one row of prothoracic bristles. Sigmactenus sulawesiensis $\mathrm{n}$. $\mathrm{sp}$. falls outside of any other group within known species of Sigmactenus and, at present, it cannot be confused with any other species. Various other characters, essentially pertaining to the genitalia (segment IX of the male, phallosome, spermatheca) confirm this observation.

Head (Figs 1, 2): haemocoels long, narrow, and in a regular band gently narrowing towards the pre-oral zone. Genal ctenidium with 10 spines in male, 11 in female: the upper-most seemingly with a sclerotised ridge and slightly accuminate (the others are rounded); in the male this spine is slightly longer than the $2^{\text {nd }}$ spine. Eye well developed. Cuticle at base of antennal fossa covered with fine parallel lines which, in some individuals, appear to be meshed together, appearing as the spermathecal strigillae of various species; this character is easily differentiated from those of other Sigmactenus where it has been described (or figured) (cf. in particular Smit, 1975). Scape without clump of dorsal bristles. Antennal pedicel lacking short bristles in male; in female, the $1^{\text {st }}$ bristle is always longer than the antennal club, the $2^{\text {nd }}$ bristle reaches (or slightly extends beyond) half the length of the club, the $3^{\text {rd }}$ is very variable (and difficult to measure) but sometimes extends to $2 / 5$ the length of the club. Occipital chaetotaxy irregular, consisting of 4-6 diffuse rows. Labial palps relatively long, always reaching trochanter (but width varying from base to apex).

Thorax (Figs 1-3). Prothorax with only one row of six bristles per side; pronotal ctenidium longer dorsally than prothorax; composed of 20-22 spines, this number not appearing to vary according to sex, with 20 being the most common figure. Uniquely, these spines always taper abruptly to a very slender point (Fig. 2), with the tips sometimes visible only at medium or high magnification. Mesothorax with three pseudo-setae (two dorsal, one ventral near the junction of the segment). Metathorax with 0-3 spinules per side, two being the most frequent number in males, one in females. Metepimeron generally with seven bristles, rarely eight (nine in two females). Pleural arch developed. Tarsal claws robust and short with very narrow separation between allex and index. False tibial combs can be considered to be present but they have sparse setae (Figs 4, 5); tibia III almost always with 11 notches (or insertions for thick bristles), of which three have double bristles, the $2^{\text {nd }}, 6^{\text {th }}$, and $11^{\text {th }}$, as a general rule. 


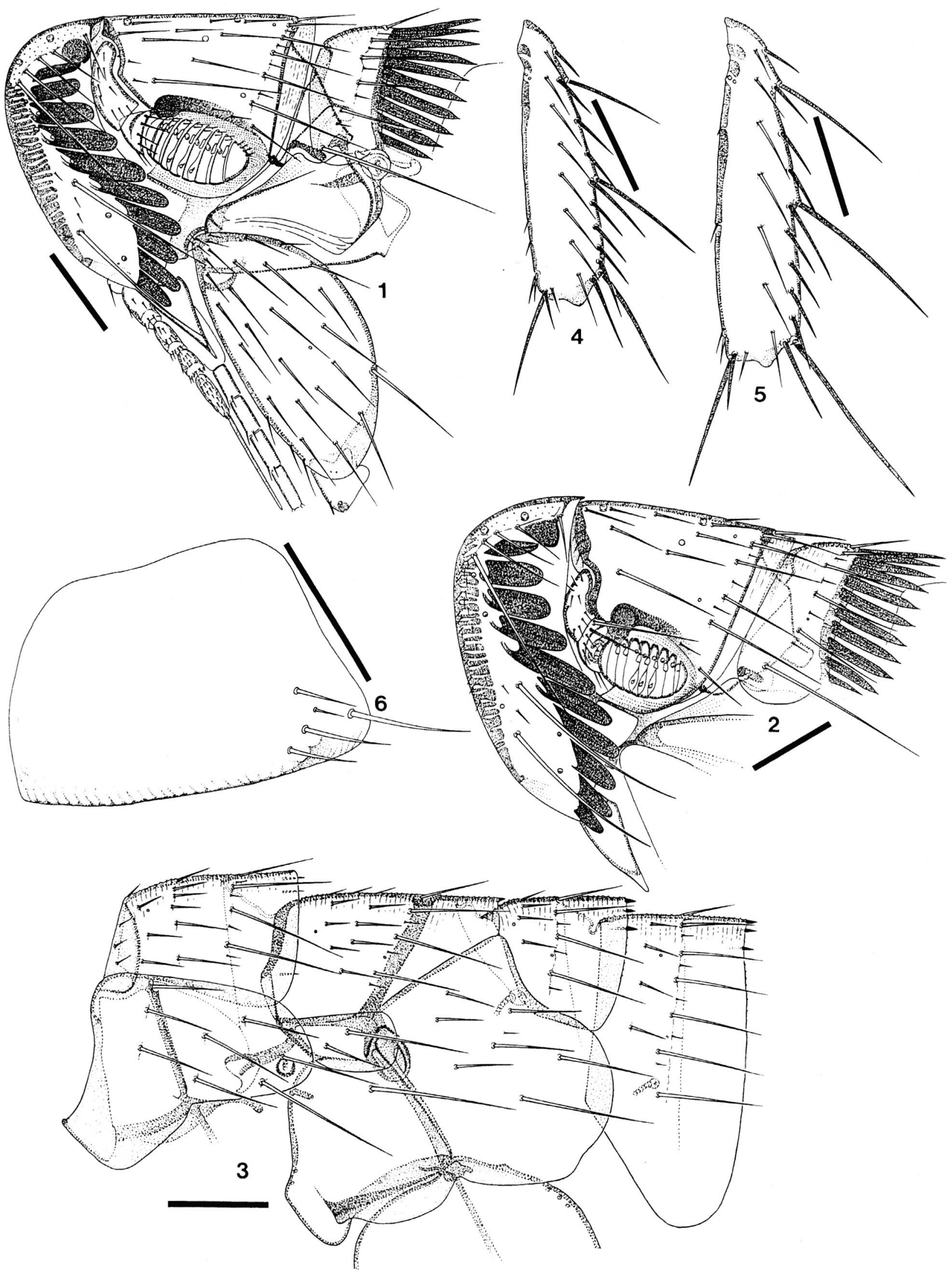

Figs 1-6. - Sigmactenus sulawesiensis n. sp. 1: Head, prothorax and adjacent structures of male. 2: Head, prothorax and adjacent structures of female. 3: Thorax of female. 4: Tibia II of female. 5: Tibia III of female. 6: Tergite VIII of male. All scale bars $=0,1 \mathrm{~mm}$. 


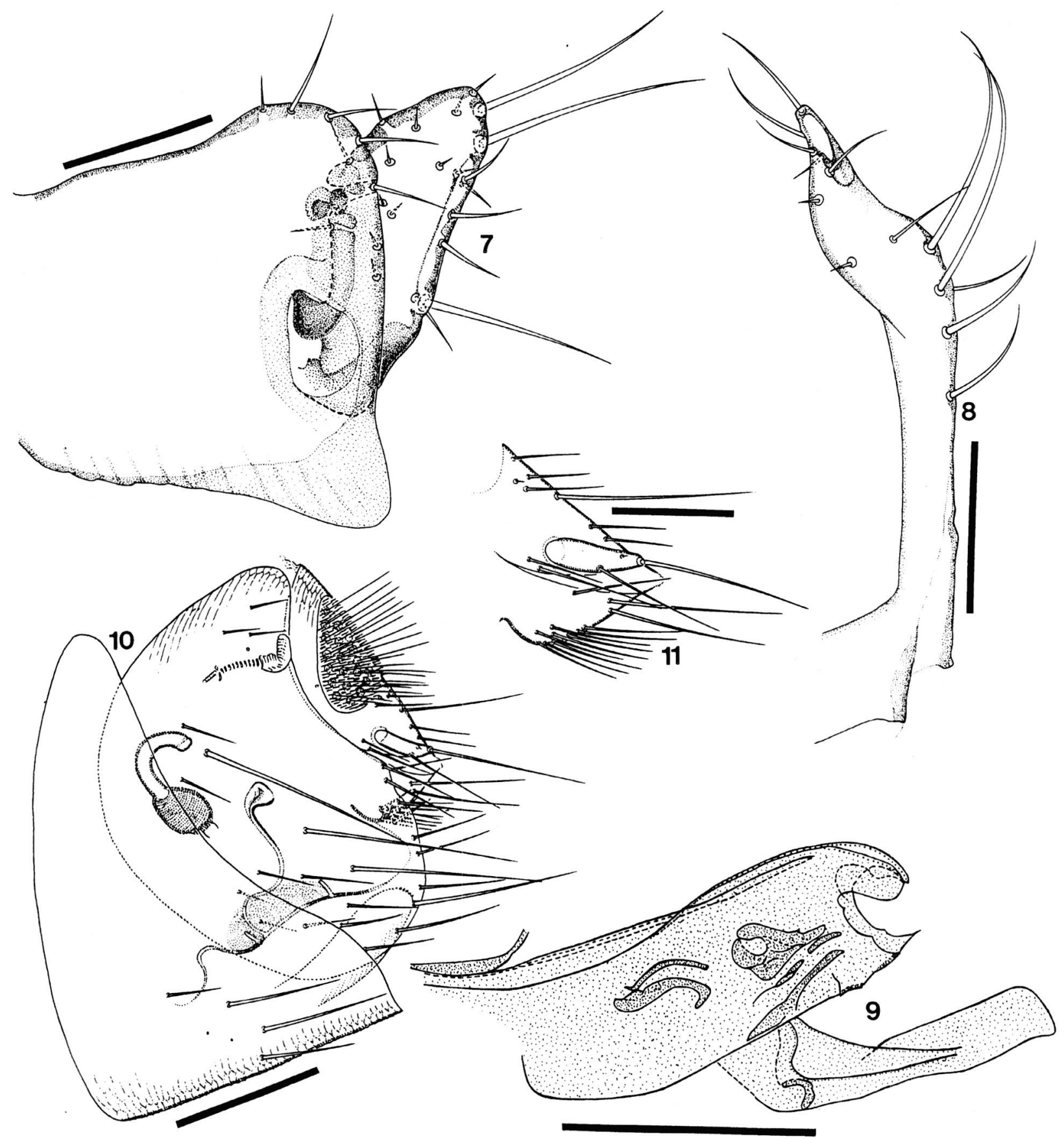

Figs 7-11 - Sigmactenus sulawesiensis n. sp. 7: Tergite IX of male. 8: Sternite IX of male. 9 : Phallosome of male. 10 : Sternite VII, spermatheca and adjacent structures of female. 11: Anal valves and anal stylet of female. All scale bars $=0,1 \mathrm{~mm}$. 
Abdomen (unmodified segments): one principal row of seven bristles (rarely eight) on each of tergites IIVII, the inferior row always being beneath the stigmata. Spinules present on at least the $1^{\text {st }}-4^{\text {th }}$ segments, rarely on the $5^{\text {th }}$, never on the $6^{\text {th }}$.

- male (average number and range of spinules per side on tergites I-VI, respectively): 2,5 (range, 2-4), 2,5 (range, 1-4), 1,9 (range, 1-3), 1,5 (range, 1-2), 0,3 (range, $0-1$ ) and 0 . Three antesensilial bristles of approximate ratio: $0,3 / 1,0 / 0,3$.

- female (as above): 2,5 (range, 1-4), 2,7 (range, 1-4), 2,5 (range, 1-4), 2.0 (range, 1-3), 0.5 (range, 0-3) and 0 . Four antesensilial bristles of approximate ratio $0,25 / 1,0 / 0,25 / 0,75$, starting from the most dorsal.

Sternites: Sternite II with one bristle; sternites III-VI each with two to three bristles in males; usually three in females.

Modified male segments: Tergite VIII (Fig. 6) relatively small, not overlapping segment IX, with 3-5 bristles, of which 2-3 are long. Sternite VIII (Fig. 6) subquadrangular with 4-7 bristles, generally with one or two of them small.

Segment IX (Figs 7-9): Basimere (Fig. 7) immediately separable from that of other Sigmactenus ${ }^{1}$ by a hyaline zone at the postero-ventral angle and making an abrupt backwards turn giving a concave contour along the posterior border of the basimere to form a massive subtriangular structure. Setation limited to posterodorsal angle terminating in a small acetabular bristle, with small bristles inserted above on the same border. Telomere robust (ratio L/l: 2,5. Range: 2,18 to 2,77) with distinctly sclerotised denticulus; three long marginal bristles, two of them close to the apex, one subbasal; less than 10 short bristles on external surface. Sternite IX (Fig. 8) angled apically, especially large in distal third; lacking spiniform bristles at apex. No spinules or teeth on basimere and/or telomere.

Phallosome (Fig. 9) very well characterized by the major development of the palliolum. Hamulus shaped as an inverse L, elongate, with principal long branch having more or less parallel sides, apex broad or slightly rounded at antero-superior angle. Dorsal sclerifications of tubus interior particularly well developed on crochet of the "armature of sclerotized inner tube" (AIT) where it re-joins the "apex of sclerotized inner tube" (ASI) (Traub, 1954). Endotendons short, extending at most to tip of lamina media.

- Modified female segments: Sternite VII (Fig. 10) without notch or lobe, with posterior border re-joining ventral border following an inferior angle of $90^{\circ}$ but not pointed. It has 4-6 bristles, of which three, some-

${ }^{1}$ The male of $S$. celebensis is not known but it must have two rows of prothoracic bristles whereas the male of $S$. sigmactenus has one; therefore, confusion between these two species is unlikely. times four, are more developed, but not extending to posterior margin. Tergite VIII rounded on posterior margin; three large lateral bristles and some accessory bristles. Sternite VIII large, rounded apically. Anal stylet (Fig. 11) variable in form (ratio L/1: 2,14 to 3,16) but setation constant: one long terminal bristle, one ventral bristle inserted between middle and distal third, one micro-bristle situated laterally.

Spermatheca (Fig. 10): Bulga ovoid, pyriform or subspherical (never round) with sparse, scaley strigillae; area cribiformis situated at opposite pole of insertion of hilla; this is arched and longer than maximum diameter of bulga. Ducti short, non-distinctive.

Dimensions (slide-mounted insects): males, 1,9 to $2,2 \mathrm{~mm}$ (average, 2,0); females, 2,0 to 2,3 $\mathrm{mm}$ (average, 2,1).

\section{SIGMACTENUS ALTICOLA PILOSUS N. SSP.}

\section{MATERIAL EXAMINED}

$\mathrm{H}$ olotype male on Rattus hoffmanni (Matschie, 1901) (prep. SS155, B87900). Indonesia, C. Sulawesi, Sungai Kanatutu (2॰04' S, $\left.119^{\circ} 58^{\prime} \mathrm{E}\right)$, 1,400 m, 11 Aug. 1973, D.F. van Peenan. Allotype female on Rattus exulans (Peale, 1848), same collection data (prep. SS153, B87899).

Paratypes (all from Indonesia: C. Sulawesi)

- On Bunomys chrysocomus (Hoffmann, 1887): $9 \mathrm{~m}$, $8 \mathrm{f}$, Lake Lindu, Tomado, 1,000 m, Aug. 1973, GGM and S. Kadarsan; $4 \mathrm{~m}, 7 \mathrm{f}$, Gunung Tambusisi (1' $38^{\circ} \mathrm{S}$, $121^{\circ} 23^{\prime}$ E), near Morawali, 1,433 m \& 1,829 m, 5-6 Mar. 1980, CHSW.

- On B. penitus: 4 m, 7 f, Gunung Nokilalaki, 2,103 m, Feb. and Mar. 1975, GGM; 6 m, 4 f, Gunung Kanino, $1,448 \mathrm{~m}$ to $1,585 \mathrm{~m}$, Oct. 1973 to Feb. 1975, GGM.

- On Bunomys prolatus Musser, 1991: 4 m, 5 f, Gunung Tambusisi, near Morawali, 1,433 $\mathrm{m}$ and $1,829 \mathrm{~m}, 10-$ 11 Mar. 1980, CHSW.

- On Bunomys n. sp. (Bunomys sp. B in Musser, 1987): $2 \mathrm{~m}, 1 \mathrm{f}$, Lake Lindu, Tomado, $1,000 \mathrm{~m}$, Jul. and Aug. 1973, GGM.

- On Margaretamys elegans Musser, 1981: $1 \mathrm{~m}$, Gunung Nokilalaki, 1,859 m; 17 Dec. 1973, GGM.

- On Maxomys hellwaldi (Jentink, 1878): 3m, 5f, Lake Lindu, Tomado, 1,000 m, 25 Aug. 1973, S. Kadarsan.

- On Maxomys wattsi Musser, 1991: 29 m, 19 f, Gunung Tambusisi, near Morawali, 1,433 m, 5-12 Mar. 1980, CHSW.

- On Maxomys n. sp. (Maxomys sp. A in Musser, 1987): 12 m, 18 f, Lake Lindu, Tomado, 1,000 m, Jul. and Aug. 1973, GGM.

- On Melasmothrix naso Miller \& Hollister, 1921: $1 \mathrm{~m}$, Gunung Nokilalaki, 2,042 m, 21 Mar. 1975, GGM. 
- On P. dominator. $8 \mathrm{~m}, 24 \mathrm{f}$, Gunung Nokilalaki, 1,707 m to 2,286 m, Dec. 1973 to Apr. 1975, GGM; 5 m, Sungai Tokararu $\left(1^{\circ} 17^{\prime} \mathrm{S}, 120^{\circ} 07^{\prime} \mathrm{E}\right), 1,150 \mathrm{~m}$, Sep. 1973, GGM; 11 m, 17 f, Gunung Kanino, 1,356 m to 1,524 m, Nov. 1973 to Apr. 1975, GGM; 4 m, 3 f, Ridge near Ranu (1' 51' S, $\left.121^{\circ} 30^{\prime} \mathrm{E}\right)$, elevation not stated, 20 Mar. 1980, CHSW.

- On R. hoffmanni: 4 m, 3 f, Lake Lindu, Tomado, 1,000 m, Jul. and Aug. 1973, GGM; 5 m, 13 f, Gunung Kanino, 1,402 m to 1,463 m, Oct. and Nov. 1973, GGM. - On Rattus marmosurus Thomas, 1921: 1f, Lake Lindu, Tomado, 1,000 m, 28 Jul. 1973, GGM.

- On Taeromys arcuatus (Tate and Archbold, 1935): 2 m, 9 f, Gunung Kanino, 1,524 m and 1,554 m, Nov. 1973, GGM.

- On Taeromys celebensis (Gray, 1867): $1 \mathrm{~m}$, Lake Lindu, Tomado, 1,000 m, 18 Aug. 1973, GGM.

- On Tateomys rbinogradoides Musser, 1969: $1 \mathrm{~m}$, Gunung Nokilalaki, 2,286 m, 20 Dec. 1973, GGM.

In addition, three female specimens without accompanying males may be $S$. a. pilosus. In all cases, specimens are not $S$. celebensis or $S$. sulawesiensis, and were collected in the absence of $S$. a. crassinavis. Collection data for these three specimens are as follows: 1) On $M$. hellwaldi, N. Sulawesi, Minahasa, Lake Iloloi ( $\left.0^{\circ} 51^{\prime} \mathrm{N}, 124^{\circ} 24^{\prime} \mathrm{E}\right), 870 \mathrm{~m}, 20$ May 1975, U.S. Naval Medical Research Unit No. 2 (NAMRU-2) team; 2) On $R$. boffmanni, C. Sulawesi, Donggala, Lembo ( $1^{\circ} 20^{\prime} \mathrm{S}$, $120^{\circ} 03^{\prime}$ E), elevation not stated, 24 Aug. 1974, NAMRU2 team; 3) C. Sulawesi, NAMRU-2 team, no other data. Because we are not certain of their identity, geographical locations of these three specimens are excluded from Fig. 35. This may be significant, because subspecies are usually separated geographically, and treating the female specimen from Lake Iloloi as $S$. a. pilosus would indicate that both it and S. a. crassinavis co-occur in N. Sulawesi. Although this might be true, analysis of the available specimens cannot definitively answer this. Even if the Lake Iloloi specimen is $S$. a. pilosus, it would still be geographically separated in N. Sulawesi from S. a. crassinavis which, at present, is only known from one mountain, Gunung Moajat.

Hosts and distribution

All 17 of the host species recorded for S. a. pilosus are murine rodents, with one of these ( $R$. exulans) being a non-native commensal rat that is widespread in the Pacific region, and the remainder all being endemic to Sulawesi. The specimen from $R$. exulans presumably reflects an accidental host association. With the exception of the female specimen of uncertain identification noted above, all examples of $S$. a. pilosus we examined are from $C$. Sulawesi at known elevations ranging from $1,000 \mathrm{~m}$ to $2,286 \mathrm{~m}$.
Etymology

The subspecific epithet of this new taxon refers to the abundant setae on the basal part of the telomere in the male. The specific epithet, alticola is derived from Maxomys alticola (Thomas, 1888), the type host of the nominate subspecies.

Deposition of types

Type deposition is the same as listed for $S$. sulawesiensis.

\section{DESCRIPTION}

Close to the nominate form described from northern Borneo, this subspecies can immediately be separated in the male by the abundant setation on the basal part of the telomere. The female, as is often the case for subspecies, is not easily separable, except in a series of specimens, by the contour of sternite VII. Sigmactenus a. pilosus is a taxon showing great variation in morphology and setation, with extreme variation occurring in specimens recovered from the same individual host. Similar intraspecific variation has previously been noted by Traub (1950) for S. werneri and by Smit (1953) for S. toxopeusi.

Head (Figs 12, 13): Shape and chaetotaxy as in $S$. $a$. alticola. Eye extremely variable ranging from vestigial to well pigmented but apparently non-functional, its form bearing no relation to host species and/or its ecology. Genal ctenidium with 8-10 spines in male (average, 9,0), and 9-11 in female (average, 10,2). Male antenna with two dense clumps of bristles on scape and, to a lesser degree, on pedicel; these are visible dorsally when the antenna is in the antennal groove, inserted on the internal surface when the antenna is erect and not easily discernible. In the female, the most dorsal bristle of the pedicel is long (at least as long as the club). Laciniae variable, extending to $3 / 5$ to $4 / 5$ (average, 2/3) of the length of coxa I.

Thorax: two rows of bristles anterior to pronotal ctenidium, with 4-7 (average 5,4) bristles in the $1^{\text {st }}$, and six or seven in the $2^{\text {nd }}$ (seven being by far the more frequent number). In one female, a $3^{\text {rd }}$ vestigial row is present anteriorly with one or two bristles on the side examined. Pronotal ctenidium with slightly rounded apical spines numbering 26 on average in both males and females (range, 24-28). Dorsally, the longest spine is equal in length to the prothorax. Mesothorax with three pseudosetae on each side inserted as in $S$. $a$. alticola; doubling or absence of the most ventral of these was observed but is exceptional. Metathorax with 0-2 spinules, generally with one. Metepimeron with 8,7 developed bristles on average (range, 8-10) in male, and 9,7 in female (range, 9-13); 1-2 vestigial supplementaries almost always present in both sexes. 


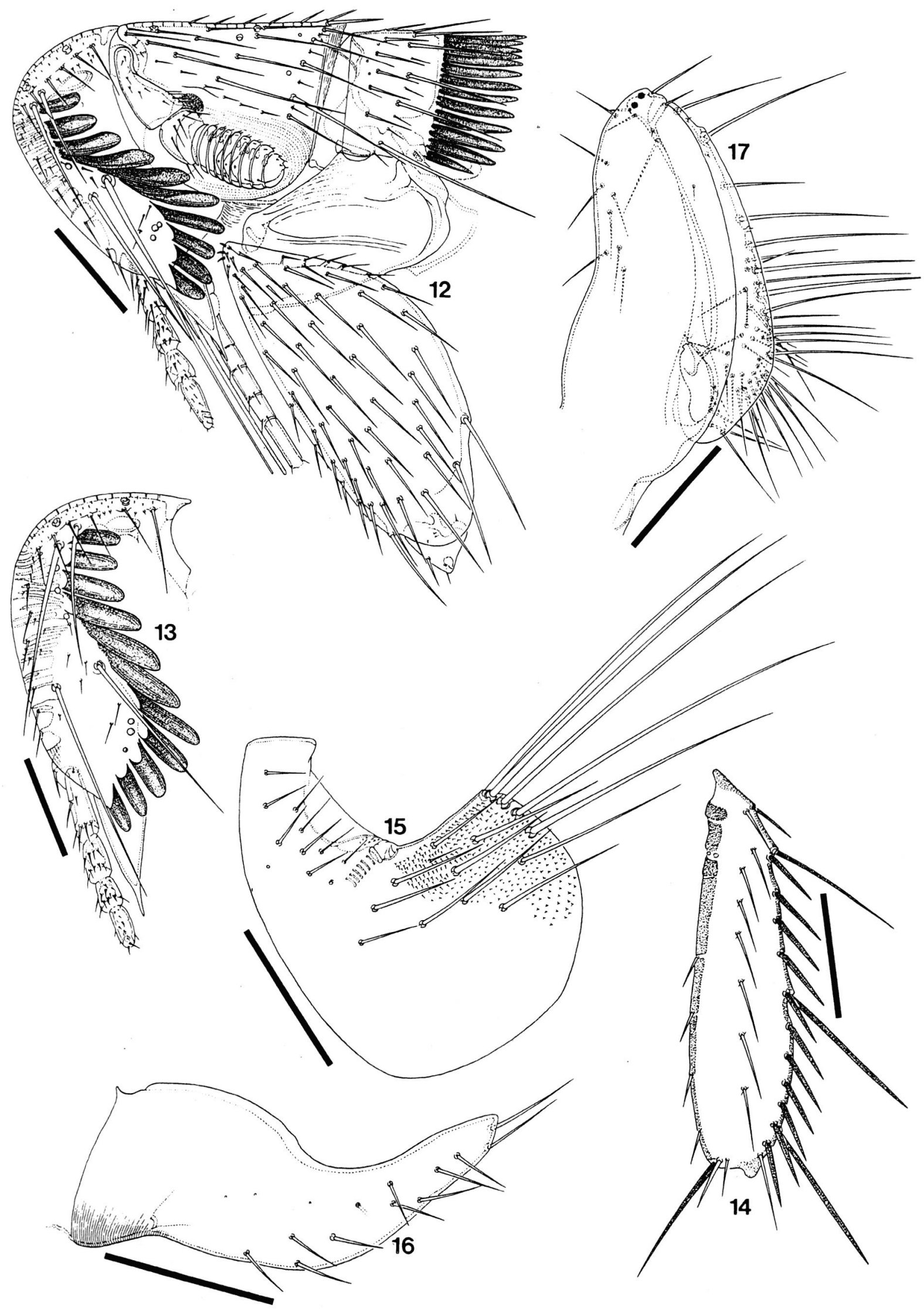

Figs 12-17. - Sigmactenus alticola pilosus n. ssp. 12: Head, prothorax and adjacent structures of male. 13: Head of female. 14: Tibia III of female. 15: Tergite VIII of male. 16: Sternite VIII of male. 17: Tergite IX of male. All scale bars $=0,1 \mathrm{~mm}$. 

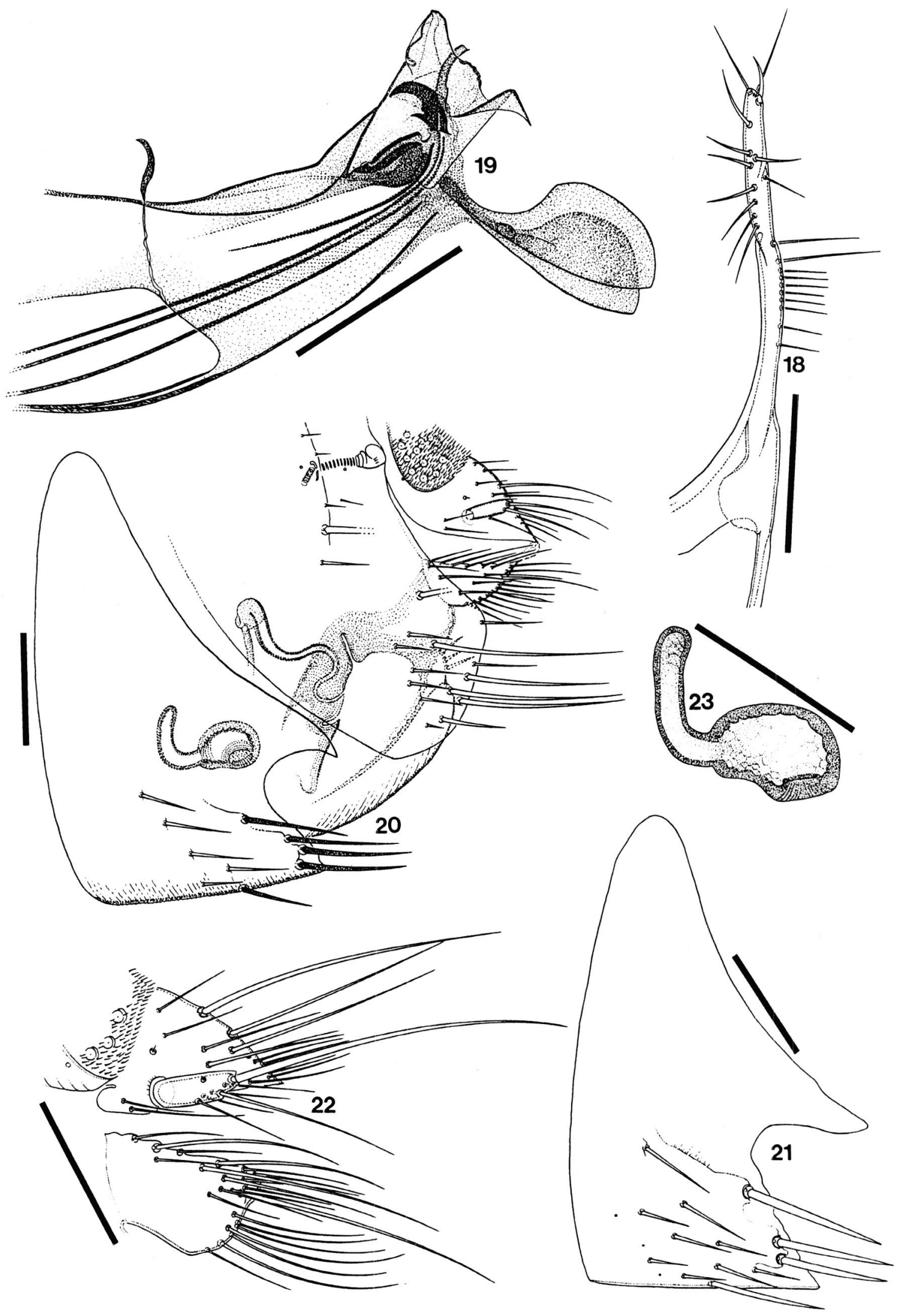

Figs 18-23 - Sigmactenus alticola pilosus n. ssp. 18: Sternite IX of male. 19: Phallosome of male. 20: Sternite VII, tergite VIII, spermatheca and adjacent structures of female. 21: Sternite VII of female. 22: Anal valves and anal stylet of female. 23: Spermatheca of female. All scale bars $=0,1 \mathrm{~mm}$. 
Tibia (Fig. 14) with false comb; on tibia III, long bristles are generally inserted in the $2^{\text {nd }}, 6^{\text {th }}$ or $7^{\text {th }}$, and $11^{\text {th }}-14^{\text {th }}$ notches. The last of these are followed by two, rarely three, shorter submarginal bristles towards the apex of the segment. All limb segments, particularly on leg III, are long; tarsal claws are short and robust. Abdomen (unmodified segments): spinules present on tergites I-IV, rarely on V, never on VI, as follows:

I: 1,7 (male) and 1,8 (female) (range, 0 [once on 1 side] to 2$)$.

II: 1,6 (male) and 1,7 (female) (range, 1 to 3 ).

III: 1,15 (male) and 1,0 (female) (range, 0 [once on 1 side] to 2$)$.

IV: 1,0 (male) and 0,8 (female) (range, 0 to 2).

$\mathrm{V}$ : 0,5 (male) and 0 (female) (range, 0 to 1 ).

Principal row of bristles on tergites II-VII with eight bristles, the most ventral being inserted below the spiracle. One bristle (rarely two) on sternite II. 2-4 (generally three) bristles on sternites III-VII in male and 34 (generally four) on sternites III-VI in female. Three antesensilial bristles present in male of average size ratio $0,25-1,0-0,3$ and four present in female of average ratio $0,25-10,-0,3-0,75$.

Modified male segments: Tergite VIII (Fig. 15) broadly rounded distally; adjacent internal surface with micro"pseudosetae" or micro-scales, often difficult to see; external surface, posterior to spiracle, with average of 13 (range, 10-16) bristles, of which 4-6 are marginal and very long, about 1,5 times longer than width of segment. Sternite VIII (Fig. 16) distinctly longer than wide, somewhat sigmoid in shape, with the apical 2/5 distinctly narrower than the basal part of the segment; chaetotaxy very variable, with 7-16 bristles, none of them long or subspiniform; two of them are slightly more developed and ventrally subapical. Tergite IX (Fig. 17): basimere narrow and elongate, with dorsal margin more or less concave, and ventral margin uniformly convex; acetabular bristle very short and subapical; no bristles on margin beneath this bristle; pigmented patches at apex (sometimes partially in relief form) present as elsewhere on the telomere. Telomere slightly arched with almost parallel sides, immediately characterized within Sigmactenus by the abundance of fine but relatively long bristles on the proximal $2 / 3$ and, particularly, the initial $1 / 3$ of the posterior margin; these bristles are marginal or inserted on the internal surface of the telomere; none are spiniform or sub-spiniform. Sternite IX (Fig. 18) with very slender distal arms; setation more abundant than in $S$. a. alticola especially along the posterior margin of the median third; one sub-spiniform bristle always present but it is subapical rather than apical (it is apical in the nominate form). Phallosome (Fig. 19): in our opinion, variation of the aedeagus does not allow differentiation from $S$. a. alticola; however, the hamulus is even more variable: it is triangular or has a rounded lobe (as in Fig. 18), although this is not the most frequent form.

Modified female segments: Sternite VII broadly indented showing much variation in shape (Figs 20, 21) and setation. Dorsal lobe overhanging the indentation and sometimes as well developed as ventral lobe but usually narrower; as an equilateral or isosceles triangle, beaked, elongate lobe with parallel sides, with a slightly rounded apex, etc.; however, it never appears as the square form present in four of five examples we examined of $S$. a alticola. The number of bristles for the entire segment is 7-14 (average, 10,5); 2-5 of these (usually 3-4) are more developed and marginal or submarginal. Tergite VIII (Fig. 20) as in S. a. alticola with equally variable chaetotaxy. Sternite VIII poorly sclerotized, slightly arched, at rounded apex. Proctiger (Fig. 22) not useful, in our opinion, for taxonomic purposes. Anal stylet (Fig. 22) variable in shape, conical or with convex sides, average dimensions are $60 \times 20 \mu \mathrm{m}$; chaetotaxy equally inconstant; most frequent setation is two apical bristles posteriorly (these can be displaced anteriorly resulting in two marginal bristles as in Fig. 22) distinctly shorter than the anterior, one marginal bristle inserted in the middle or $2 / 3$ from the ventral border, and one subdorsal micro-bristle.

Spermatheca and ducti: Ducti not separable from those of $S$. a. alticola (based on specimens from the collections of LAD and in the Natural History Museum, London; these structures were not illustrated by Traub, 1954). Spermatheca always showing, but to varying degrees (Figs 20, 23), bulga longer than high, billa more or less arched and longer than bulga.

Dimensions (slide-mounted insects): males 2,0 to $2,5 \mathrm{~mm}$ (average, 2,3); females 2,3 to $3,0 \mathrm{~mm}$ (average, 2,65).

\section{SIGMACTENUS ALTICOLA CRASSINAVIS N. SSP.}

\section{MATERIAL EXAMNINED}

$\mathrm{H}$ olotype male, on B. fratrorum (prep. B98897). Indonesia, N. Sulawesi, Gunung Moajat, 1,780 m, Aug. 1985, CHSW. Allotype female on P. dominator, same location, 1,650 m, Mar. 1985, LAD (LAD85).

Paratypes (all collected in N. Sulawesi on Gunung Moajat).

- On B. fratrorum: 2 m, 1,780 m, Aug. 1985, CHSW. - On M. musschenbroekii: 3 f, 1,200 m, 1 Aug. 1985, B.F. Page; 1 m, 1 f, 1,780 m, Aug. 1985, CHSW.

- On P. dominator. 13 m, 7 f, 1,650 \& 1,780 m, Mar. and Aug. 1985, LAD or CHSW.

- On $R$. hoffmanni: 3 m, 3 f, 1,780 m, Aug. 1985, CHSW. 
- On Rattus xanthurus (Gray, 1867): 1 f, Aug. 1985, CHSW.

- On Crocidura sp.: 4 f, ca. 1,150 m, Aug. 1985, CHSW.

Hosts and distribution

This subspecies was recorded from one species of endemic shrew (Crocidura sp.) (Insectivora: Soricidae: Crocidurinae) and five species of endemic murine rodents from a single mountain (Gunung Moajat) in N. Sulawesi at elevations ranging from $1,150 \mathrm{~m}$ to $1,780 \mathrm{~m}$.

Etymology

The Latin derivation of the name crassinavis is for crassus (= thick) and navis (= sternum [of a bird]) in reference to the thickened sternum VIII of the male of this subspecies.

\section{Deposition of types}

Type deposition is the same as listed previously for $S$. sulawesiensis and S. a. pilosus.

\section{DESCRIPTION}

This subspecies is easily separated from $S$. a. alticola and $S$. a. pilosus by the hypertrophy of sternite VIII in the male. We noted less variation in this new subspecies than in S. a. pilosus.

Head: As in S. alticola s. 1. Eye pigmentation generally more marked than in $S$. a. pilosus but, exceptionally, can be absent. Genal ctenidium with nine spines in male and 10 (exceptionally, 11) in female. Antennal setation of male typical for $S$. alticola; in female, the longest bristle on the pedicel is slightly less developed than in S. a. alticola and S. a. pilosus, extending at most, to apex of antennal club, with the next seta being slightly shorter.

Thorax: prothorax as in other subspecies; pronotal ctenidium with 26-28 spines in male, 26-30 in female. Mesothorax with 2-4 pseudosetae in both sexes (three is the usual number in S. a. alticola and S. a. pilosus). Metathorax with 0-2 spinules on each side (average, 1,5); metepimeron with 9,8 bristles on average (range, 9-11) in male, not counting vestigial bristles almost always present, slightly more than 10 (range, 9-11) in female. Legs lacking typical characters.

Abdomen (unmodified segments): spinules present on tergites I-IV, rarely on V (only in male), never on VI; respectively (on average):

I: 2,0 (male), 2,3 (female)

II: 2,0 (male), 1,8 (female)

III: 1,6 (male), 1,0 (female)

IV: 1,3 (male), 0,6 (female)

$\mathrm{V}: 0$ (1 once on 1 specimen) (male), 0 (female)

Same tergal setation as in other subspecies. Sternite II with one, rarely two, bristles; sternites III-VII of male each with three bristles; sternites III-VI of female each typically with four bristles (range, 3-5).

Modified male segments: Tergite VIII as in $S$. a. alticola: with 10 bristles on average on apical process with 3-5 of these being marginal. Internal surface with classical micro-"pseudosetae." Sternite VIII (Fig. 24) unique to this subspecies: the general form is that of $S$. alticola s. 1 . but the anterior $2 / 3$ are large (from which the subspecific epithet is derived) compared to other subspecies. Apical (or apico-distal) process very short with one bristle clearly implanted at apex; a $2^{\text {nd }}$ bristle is sometimes contiguous subventrally. The apical bristle is generally longer than other bristles of this segment which number 12 on average (range, 8-16). Tergite IX (Fig. 25) not discernable from that of the nominate subspecies. Sternite IX (Fig. 26) characterised, like the nominate form, by one apical subspiniform bristle; shape of sternite and chaetotaxy also identical to that of S. a. alticola.

Phallosome (Fig. 27) like that of S. a. pilosus; slightly different from that of the nominate form in that the mediodorsal lobe of the tubus interior (MDL of Traub, 1954) is narrower than the armature of this tubus (AIT of Traub, 1954). Form of hamulus constant in our series - lanceolate (like a half-leaf of willow[Salix]) at acuminate apex.

Modified female segments: Sternite VII (Figs 28-31) with large concave sinuous posterior margin; superior lobe always long and generally narrow but variable in form. Number of bristles per side is 12 on average (range, 10-14) of which 2-4 are robust and marginal or submarginal. Tergite and sternite VIII: proctiger as in other subspecies. Anal stylet variable having on average $L / 1$ ratio of $1,9 / 0,7$; generally with two apical bristles, one ventral bristle, rarely one median bristle, and always sub-dorsal micro-bristle.

Spermatheca (Fig. 34) and ducti not distinctive; however, billa is long, perpendicular to bulga, and usually subrectangular.

Dimensions (slide-mounted insects): males 2,3 to 2,4 $\mathrm{mm}$ (average, 2,35); females 2,6 to 3,0 $\mathrm{mm}$ (average, 2,75).

Discussion concerning the subspecies of $S$. alticola ${ }^{2}$ Since the general characters of the Bornean S. alticola s.s. are clearly repeated in the two taxa that we describe here from Sulawesi, it invites an analysis of the precise relationship between these three taxa. They cannot be considered to be distinct species because segment IX of the male and the phallosome are morphologically too close in all three forms. In fact, their

\footnotetext{
${ }^{2}$ We have examined 13 specimens of S. alticola s.s. (one male paratype, two female topotypes from the collection of LAD, and five males, five females from the paratypes and topotypes in the Natural
} History Museum, London, all collected by R. Traub). 


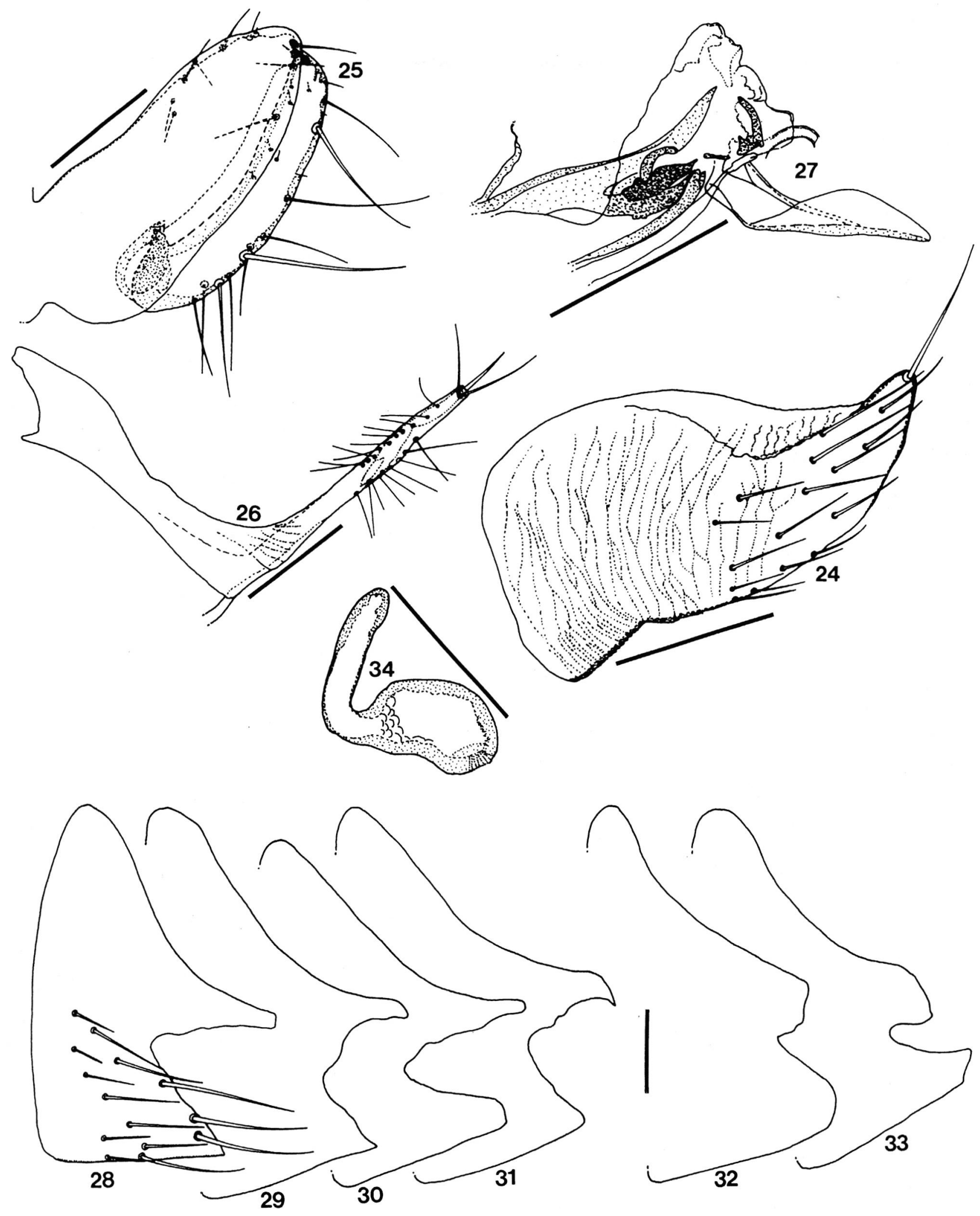

Figs 24-34. - Sigmactenus alticola crassinavis n. ssp. and S. a. alticola. 24: S. a. crassinavis, Sternite VIII of male (holotype). 25: S. a. crassinavis, Tergite IX of male (holotype). 26: S. a. crassinavis, Sternite IX of male (holotype). 27: S. a. crassinavis, Phallosome (aedeagus) of male (holotype). 28-31: S. a. crassinavis, Sternite VII of female showing variation (28: allotype, 29-31: paratypes). 32, 33: S. a. alticola Sternite VII of females (topotypes) showing variation. 34: S. a. crassinavis, Spermatheca of female (paratype). All scale bars $=0,1 \mathrm{~mm}$. 
autonomy is so close that sub-speciation is evident. Sigmactenus $a$. pilosus can be differentiated from the other two subspecies by the setose appearance of the telomere and the less distinct setation on sternite IX (subspiniform bristle not apical, setation of posterior edge of distal segment implanted more ventrally). Sigmactenus a crassinavis is characterized by the hyperdevelopment of sternite VIII. It shares with $S$. a. alticola, the same chaetotaxy on sternite IX, although this is more developed in $S$. a. crassinavis. The female of S. a. crassinavis has a more developed lobe on sternite VII; it is the opposite in $S$. a. alticola (Figs 32, 33), and less distinct in S. a. pilosus (Figs 20, 21).

\section{IDENTIFICATION KEY}

\section{TO KNOWN SPECIES AND SUBSPECIES}

\section{IN THE GENUS SIGMACTENUS}

$\mathrm{H}$ opkins \& Rothschild (1971) provided a key to the three species of Sigmactenus known at that time. Lewis \& Jones (1985) prepared a new dichotomous key after the number of described species in this genus rose from three to five. Durden \& Beaucournu (2000) excluded one of these (S. cavifrons which they placed in synonymy with $S$. toxopeusi Smit, 1953) and described $S$. timorensis as a new species. Because the present work describes three new taxa, we provide here an updated key to the genus.

1 - One row of prothoracic bristles anterior to ctenidium .............................................sulawesiensis

- Two rows of prothoracic bristles anterior to ctenidium

- Males (the male of celebensis is unknown) .......3

- Females .................................................................. 8

3 - Tergite VIII typically with two postero-dorsal marginal or submarginal bristles ...4

- Tergite VIII typically with 4-6 postero-dorsal marginal or submarginal bristles .5

- Sternite VIII about as long as high toxopeusi $(=\text { cavifrons })^{3}$

- Sternite VIII much longer than high, with a long slender apical process..............timorensis

5 - Apex of distal arms of sternite IX with a very distinct spiniform bristle; basimere more than four times as long as broad; sternite VIII massive, not narrowing apically werneri

- One small spiniform bristle or apical/preapical subspiniform on distal arms of sternite IX; basi-

${ }^{3}$ If $S$. cavifrons is a subspecies of $S$. toxopeusi as suggested by Durden \& Beaucournu (2000) and not a complete synonym, the first can be separated from the second by the concave profile (as opposed to rectilinear or convex) of the head capsule. mere 2,5 times (or less) as long as wide; sternite VIII more or less sigmoid and distinctly narrowed apically ...................(alticola ssp.) .......6

- Telomere: basal half distally (and on internal surface) with less than 10 bristles; one small apical spiniform bristle on sternite IX ..........7

- Telomere: many more than 10 bristles on basal half; one small subapical spiniform bristle on sternite IX alticola pilosus

7 - Sternite VIII only narrowed at apex alticola crassinavis

- Sternite VIII narrowed in distal 2/5 alticola alticola

- Sternite VII lacking indentation; bulga subspherical, with area cribriformis ventral to billa. celebensis

- Sternite VII with indentation (sometimes small in toxopeusi); bulga more cylindrical than subspherical .9

- Marginal and submarginal bristles absent on stèrnite VII ..................................................10

- Marginal or submarginal bristles present on sternite VII ...................................................11

10 - hilla longer than bulga; dorsal and ventral lobes of sternite VIII nearly symmetrical toxopeusi $(=\text { cavifrons })^{3}$

- billa shorter than bulga; dorsal lobe of sternite VIII more slender and acuminate than ventral lobe......................................................timorensis

11 - Ventral valve of proctiger triangular typically with three bristles inserted at the postero-ventral angle werneri

- Ventral valve of proctiger more subquadrangular and with several bristles at the postero-ventral angle ...............................(alticola ssp.)...12

$12^{4}$ - Dorsal lobe of sternite VII short and obtuse alticola alticola

- Dorsal lobe of sternite VII long ....................13

13 - Dorsal lobe of sternite VII generally in the shape of an isosceles triangle, usually acuminate...........................................alticola pilosus

- Dorsal lobe of sternite VII generally rod-shaped at apex and generally obtuse, occasionally hooked alticola crassinavis

\section{DISCUSSION}

W ith the description of the new taxa described in this paper, three species of Sigmactenus are now known from Sulawesi. One of these species is further separated into two dis-

${ }^{4}$ Characters very variable; identification tenuous in absence of males. 


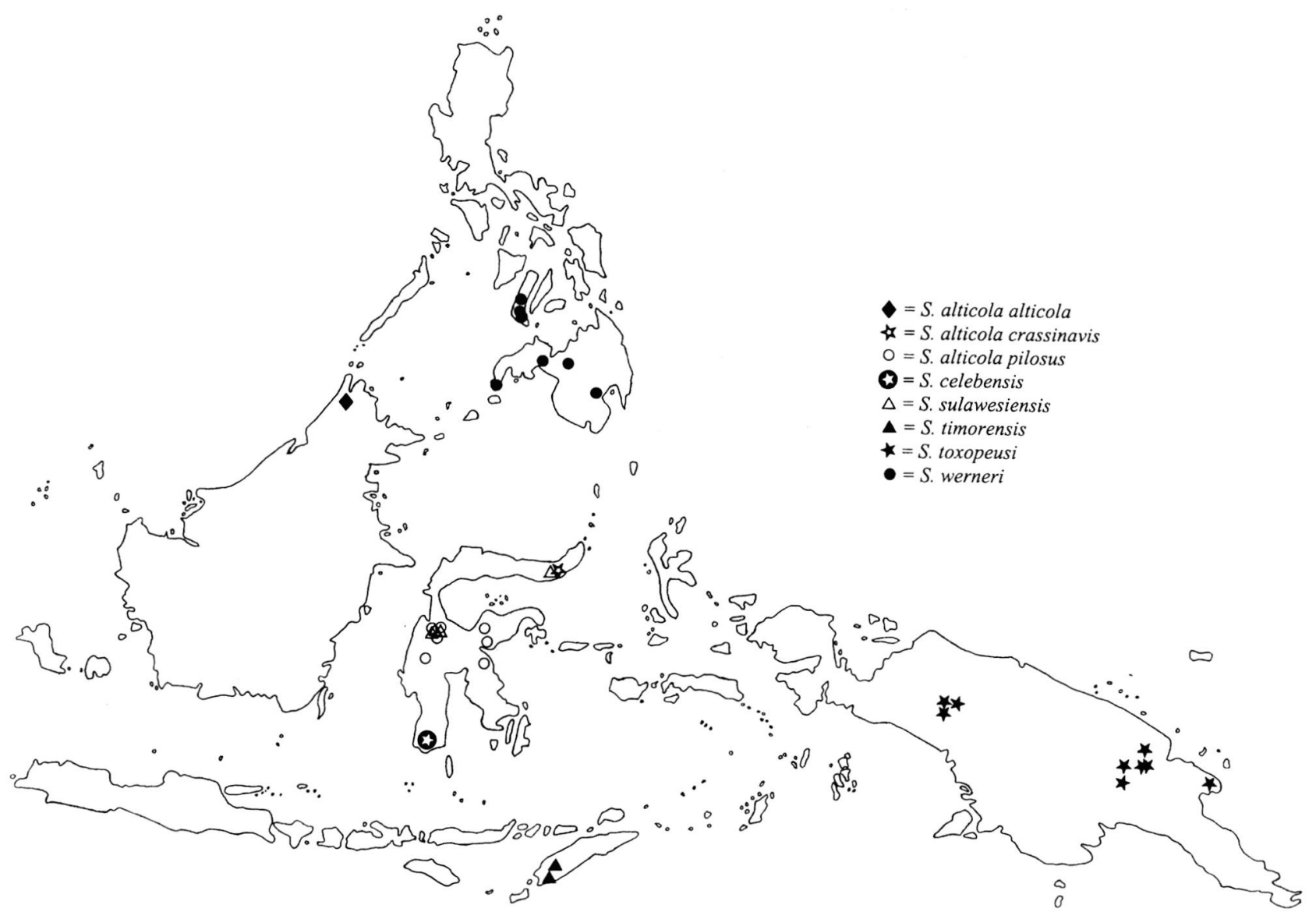

Fig. 35. - Map of the Indo-Australian region showing known geographical distributions of described species and subspecies of Sigmactenus.

tinct subspecies which appear to be separated geographically. This means that more Sigmactenus taxa are now known from Sulawesi than from any other island (Fig. 35). As with other described species of Sigmactenus, the Sulawesi taxa are mainly ectoparasites of endemic murine rodents, with a few specimens recovered from an endemic squirrel, an endemic shrew, and a wide ranging commensal rodent. In fact, endemic murines appear to be the preferred hosts of all described taxa of Sigmactenus. However, the New Guinean $S$. toxopeusi has also been recovered from endemic small marsupials or widely distributed commensal rats (Smit, 1953, 1975; Holland, 1969) and a few collections of $S$. werneri in the Phillipines are from native shrews or commensal rats (Durden \& Beaucournu, 2000).

Sulawesi is a large oceanic island that evidently has not had land connections to any other large landmass (Musser, 1987). Although the immediate ancestors of most of Sulawesi's extant mammals clearly colonised the island from Asia, relatively few groups of mammals were able to successfully disperse to Sulawesi and many of those that did, radiated into endemic species clusters (Musser, 1987). For example, native endemic murines, which are the main hosts of Sigmactenus spp. fleas, are currently represented on Sulawesi by species clusters of Bunomys (nine species), Margaretamys (three species), Maxomys (six species), Rattus (nine endemic species as well as five commensal species), and Taeromys (eight species) (Musser \& Holden, 1991).

Because the area of origin for many taxa often has the most diverse extant fauna for the taxon in question (Briggs, 1984), the genus Sigmactenus could have evolved on Sulawesi before dispersing to other IndoAustralian islands with its murine hosts and then speciating further. Although this scenario is possible, based on the area of origin of the ancestors of Sigmactenus, their host relationships, and the geological history of Sulawesi, it seems more plausible that Sigmactenus fleas first colonised Sulawesi as ectoparasites of murines (probably Maxomys spp. or Rattus spp.) as they dispersed from Asia a few million years ago. Sigmactenus is derived from Leptopsylla Jordan and Rothschild (subgenus Pectinoctenus Wagner) which has Palaearctic roots (Durden \& Traub, 1990; Durden \& 
Beaucournu, 2000) so the prevailing direction of island colonisation in this region by these fleas was from mainland Southeast Asia, southwestwards into Indo-Australia. Further support for this dispersal route lies in the fact that the Bornean S. alticola alticola is only known to parasitise Maxomys alticola (Traub, 1954) and all of the Sulawesi Sigmactenus taxa appear to be associated to varying degrees with endemic species of Maxomys. Sigmactenus celebensis, although known from just one specimen, was recovered from M. musschenbroekii in South Sulawesi (Lewis \& Jones, 1985). We recorded S. sulawesiensis n. sp. from five species of endemic Sulawesian murines and one species of endemic squirrel with one (6\%) of the 18 specimens being collected from Maxomys (again this was M. musschenbroekii). Our records show that $S$. alticola pilosus n. ssp. was recovered from one commensal and 15 endemic species of murines with 87 (34\%) of the 256 specimens recovered from Maxomys spp. We recorded $S$. alticola crassinavis $\mathrm{n}$. ssp. from five species of endemic murines and one species of endemic shrew with five (12\%) of the 41 specimens recovered from Maxomys (all from M. musschenbroekii).

Although six endemic species of Maxomys are known to inhabit Sulawesi, the origins of this murine genus are in the Greater Sunda region (mainland Southeast Asia together with the Greater Sunda islands of Sumatra, Java and Borneo, all of which were contiguous during Pleistocene ice ages when eustatic sea levels dropped by as much as $200 \mathrm{~m}$ ) (Durden \& Traub, 1990; Musser, 1981, 1987, 1991; Musser et al., 1979). However, Maxomys is one of only two native murine genera that successfully reached Sulawesi from the Sundaic region. The other genus is Rattus which is currently represented on Sulawesi by five non-native commensal species and by nine endemic species (Musser \& Holden, 1991). Therefore, it is also possible that Sigmactenus reached Sulawesi by accompanying the colonizing species of native Rattus from the Sundaic region. In support of this colonisation scenario, Sigmactenus occurs on large islands to the north (Mindanao, Negros) and east (Timor, New Guinea) of Sulawesi (Traub, 1950; Durden \& Beaucournu, 2000) which are inhabited by native species of Rattus but not by Maxomys. However, contrary to this scenario, relatively few of the Sulawesi Sigmactenus specimens have been recorded from native Rattus spp. ( $0 \%$ of $S$. celebensis, $0 \%$ of S. sulawesiensis, $9 \%$ of S. alticola pilosus, $17 \%$ of S. alticola crassinavis). The hosts of S. toxopeusi on New Guinea are almost equally divided between native small marsupials, Rattus spp. or Melomys spp. (Smit, 1953, 1975; Holland, 1969). The marsupial hosts are presumably accidentals but the Rattus and Melomys host records are of interest because
Sigmactenus may have accompanied native species of Rattus across the Indo-Australian archipelago, or it may have switched from Maxomys to Melomys east of Sulawesi where Maxomys does not occur (Musser et al., 1979). The significance of Melomys being an important host on New Guinea, and possibly also on Timor (Durden \& Beaucournu, 2000), is that Melomys is the morphological and ecological convergent equivalent of Maxomys (Musser et al., 1979). Although unlikely, it is also possible that Sigmactenus fleas dispersed to Sulawesi as ectoparasites of the Sundaic ancestors of one or more of Sulawesi's other endemic murines because all 54 species of native rodents that are known to inhabit Sulawesi have Sundaic origins (Musser, 1981, 1987; Musser \& Holden, 1991).

\section{ACKNOWLEDGEMENTS}

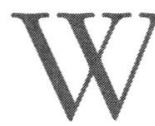

e thank Guy G. Musser (American Museum of Natural History, New York, USA), Sampurno Kadarsan (Bogor, Indonesia), Christopher H.S. Watts (South Australian Museum, Adelaide) and former members of NAMRU-2 (Jakarta, Indonesia) for collecting some of the fleas reported in this study. Guy Musser also identified mammalian hosts. We also thank the late Robert Traub (Bethesda, Maryland, USA) for helpful discussions on the taxonomy of the genus Sigmactenus, and both R. Traub and Thomas M. Evans (Arizona, USA) for their input on the drawings of $S$. sulawesiensis and $S$. alticola pilosus. Theresa M. Howard (The Natural History Museum, London, UK) arranged a loan of S. alticola type material.

\section{REFERENCES}

BRIGgS J.C. Centres of origin in biogeography. Biogeographical Monographs, 1984, 1, 1-106.

Durden L.A. \& BeAucournu J.-C. The flea genus Sigmactenus (Siphonaptera: Leptopsyllidae): a new species from Timor and new material from New Guinea and the Philippines. The Journal of Parasitology, 2000, 86, 432-437.

Durden L.A. \& Traub R. Zoogeographical implications from rodent ectoparasites in Sulawesi. In: W.J. Knight \& J.D. Holloway (Editors), Insects and the rain forests of South East Asia (Wallacea), Royal Entomological Society, London, 1990, pp. 57-62.

Holland G.P. Contribution towards a monograph of the fleas of New Guinea. Memoirs of the Entomological Society of Canada, 1969, 61, 1-77.

HopkINS G.H.E. \& RoTHSCHILD M. An illustrated catalogue of the Rothschild collection of fleas (Siphonaptera) in the British Museum (Natural History). Vol. V: Leptopsyllidae and Ancistropsyllidae. 1971: British Museum. 530 pp., 30 pl. 
LEwIS R.E. \& Jones G.S. Some fleas (Siphonaptera) from Sulawesi Selatan, with the description of three new species. Journal of Medical Entomology, 1985, 22, 204-211.

Musser G.G. Results of the Archbold Expeditions. No. 105. Notes on systematics of Indo-Malayan murid rodents, and descriptions of new genera and species from Ceylon, Sulawesi, and the Philippines. Bulletin of the American Museum of Natural History, 1981, 168, 225-334.

Musser G.G. The mammals of Sulawesi. In: T.C. Whitmore (Editor), Biogeographical evolution of the Malay Archipelago, Clarendon Press, Oxford, 1987, pp. 73-93.

Musser G.G. Sulawesi rodents: descriptions of new species of Bunomys and Maxomys (Muridae, Murinae). American Museum Novitates, 1991, 3001, 1-41.

Musser G.G. \& Holden M.E. Sulawesi rodents (Muridae: Murinae): morphological and geographical boundaries of species in the Rattus hoffmanni group and a new species from Pulau Peleng. Bulletin of the American Museum of Natural History, 1991, 206, 322-413.

Musser G.G., Marshall J.T. \& Boedi. Definition and contents of the sundaic genus Maxomys (Rodentia, Muridae). Journal of Mammalogy, 1979, 60, 592-606.

Smit F.G.A.M. Results of the Archbold Expeditions. No. 70. Siphonaptera from Netherlands New Guinea. Part I. American Museum Novitates, 1953, 1638, 1-53.

SMIT F.G.A.M. Sigmactenus cavifrons, a new flea from New Guinea. Entomologische Berichten, 1975, 35, 65-68.

Traub R. Sigmactenus, a new genus of flea from the Philippines. Journal of the Washington Academy of Science, 1950, 40, 371-378.

Traub R. Sigmactenus alticola and Neopsylla luma, new species of fleas from North Borneo. Malaysian Parasites XI. Studies from the Institute of Medical Research, Federation of Malaya, 1954, 26, 184-194.

Reçu le 29 juin 2000

Accepté le 7 juillet 2000 